\title{
The Influence of Different Meanings of Money Priming on Consumer's Comparative Decision-Making
}

\author{
Hong Zhou, Xiaomin Wei \\ The School of Management, Jinan University, Guangzhou, China \\ Email: shawmmm@163.com
}

How to cite this paper: Zhou, H., \& Wei, X. M. (2020). The Influence of Different Meanings of Money Priming on Consumer's Comparative Decision-Making. Open Journal of Social Sciences, 8, 180-193. https://doi.org/10.4236/jss.2020.83016

Received: February 17, 2020

Accepted: March 13, 2020

Published: March 16, 2020

Copyright () 2020 by author(s) and Scientific Research Publishing Inc. This work is licensed under the Creative Commons Attribution International License (CC BY 4.0).

http://creativecommons.org/licenses/by/4.0/

\section{(c) (i) Open Access}

\begin{abstract}
With the development of information dissemination, consumers have access to compare different information before making purchase decisions. The present research explores how money priming affects consumers' comparative decision-making process. While prior research showed that consumers rely more on alignable than nonalignable attributes when evaluating alternative products, this research builds on the structural alignment model and money priming theory verifies that when the concept of abundant (vs. lack) money is primed, consumers will rely more on the nonalignable (vs. alignable) attributes in the comparative decision-making process (Study 1) and the mediating role of cognitive flexibility (Study 2).
\end{abstract}

\section{Keywords}

Money Priming, Comparative Decision Making, Structural Alignment Model, Cognitive Flexibility

\section{Introduction}

With the advent of the Internet era, it becomes more convenient for consumers to search information, which helps them have access to compare the advantages and disadvantages of alternative products choices, and make decisions after weighing and comparing them.

In order to attract consumers in the market competition, many enterprises adopt different strategies to ensure that their products stay ahead (Kotler, Keller, Brady, Goodman, \& Hansen, 2009). In the differentiation strategy, some enterprises focus on obtaining advantages on the common attributes that all options have (i.e. alignable attributes), while others focus on acquiring advantages on 
unique attributes that are not available in other options (i.e. nonalignable attributes) (Gentner \& Markman, 1997).

The past researches of structural alignment model suggested that consumers rely more on alignable than nonalignable attributes when they make choice (Markman \& Medin, 1995; Gentner \& Markman, 1997). However, some factors would affect consumers' reliance, like cognitive resources (Kivetz \& Simonson, 2000), or individuals' need for cognitive closure (Zhang, Karde, \& Cronley, 2002), or cognitive ability (Nam, Wang, \& Lee, 2012), or some other factors which will affect individuals' cognition.

Money, in addition to influencing consumers as an obvious price mark, Vohs, Mead, \& Goode (2006) proposed that when the concept of money is primed through psychological priming technology, it can also affect individuals unconsciously as a potential variable in the environment. Further, as a symbol of resources, money can have different effects when priming different amounts of money concepts. For example, Hansen, Kutzner, \& Waenke (2013) found that when reminders of a great deal of (vs. lack) money would facilitate global, abstract mental construals (vs. more concrete mental representations).

According to previous research findings, money priming with different meanings can bring changes in individual cognition, and the changes in cognitive state will affect consumers' reliance on different attributes in comparative decisionmaking. So we further explore the influence of different meanings of money priming on the reliance of alignable and nonalignable attributes.

\section{Theoretical Background}

\subsection{Comparative Decision Based on Structure Alignment Model}

When consumers make purchase decisions, they usually evaluate and compare multiple choices of similar products, so as to form the final purchase intention. This process of comparing the advantages and disadvantages of alternative choices is the process of consumers' comparative decision making (Sun, 2014). Previous studies on comparative decision making are mostly based on structural alignment model (Zhang \& Markman, 1998; Zhang \& Markman, 2001; Sun, 2010).

Specifically, the structural alignment model refers to the comparison between the information of alternative choices by consumers. In addition to the same attributes and value of all choices, other attributes can be classified into two categories: one is the alignable attribute, and the other is the nonalignable attribute. Alignable attribute refers to that different choice have the same attribute at the same time, only the value has difference in this attribute and nonalignable attributes refer to the unique and differentiated attributes of each choice (Markman \& Medin, 1995). For example, if Tablet $\mathrm{M}$ and $\mathrm{N}$ both show the information of their battery life, Tablet $\mathrm{M}$ is 8 hours and Tablet $\mathrm{N}$ is 6 hours with the same other configuration information, then the battery life is the alignable attribute in these two products. If Tablet $\mathrm{N}$ supports the face recognition function, but Tablet $\mathrm{M}$ does 
not have this function, then the face recognition function is the nonalignable attributes between these two products.

Alignable attributes have stronger comparability in the same dimension and are easier to be processed in individuals' cognition (Gentner \& Markman, 1994). However, the processing of nonalignable attributes usually requires more cognitive resources and efforts (Markman \& Medin, 1995). Therefore, in the initial studies on structural alignment models, many researchers have proved that compared with nonalignable attributes, consumers are more inclined to rely on alignable attributes when making comparative decisions (Zhang \& Fitzsimons, 1999).

However, with the development of the structural alignment model, it is found that nonalignable attributes are more unique to consumers (Nam, Wang, \& Lee, 2012). When consumers have cognitive ability or resources to process complex information (Zhang \& Markman, 2001), or when they have lower need for cognitive closure (Zhang, Karde, \& Cronley, 2002), or when they make decisions from a distant future than for those in the near future (Malkoc et al., 2005), or make decisions from an abstract and comprehensive perspective (Sun, Keh, \& Lee, 2019), or under the influence of other cognitive or information processing factors (Sun, 2014), they will increase the reliance on nonalignable attributes and weaken the influence by alignable attributes in the decision-making process.

In conclusion, consumers' dependence on alignable attributes is not immutable. Many cognitive factors and external environmental factors can increase consumers' attention to nonalignable attributes in the process of comparative decision making.

\subsection{Money Priming}

The concept of money priming was first proposed by Vohs, Mead \& Goode (2006) on Science, who studied "money" as a specific concept rather than property or ownership. Money priming is the unconscious activation of individuals' thoughts about money through the use of psychological priming technology, thus changing consumers' cognition of the availability of money.

Money as a symbol has always been associated with various types of resources, such as security, status, power, self-confidence and freedom (Matthews, 1991; Goldberg \& Lewis, 2000). Therefore, different amount of money has different meanings to individuals. According to the research of social economics, the possession of abundant money resources can improve individual's sense of control over the results and protect the individual from being affected by the unfortunate or unforeseen events in life. However, the lack of money resources will lead individually depressed and has low sense of control (Johnson \& Krueger, 2006; Mogilner, 2010). That is, the different amount of money owned by individuals may lead to different psychological changes. So according to the different amount of money, previous scholars divided the meanings of money priming into abundant money (i.e., stimulate individuals' idea of having abundant mon- 
ey) and lack money (i.e., stimulate individuals' idea of having a little money) prime.

Zhou, Vohs, \& Baumeister (2009) proposed that the concept of abundant (vs. lack) money can make individuals believe that external factors are more controllable, so as to enhance their strength, self-confidence and self-efficacy when dealing matters. And the concept of abundant money makes individuals stick longer durations in challenging tasks (Vohs, Mead, \& Goode, 2006). Besides, reminders of abundant versus lack money facilitate global, abstract mental construals on cognition level (Hansen, Kutzner, \& Waenke, 2013). In addition, individuals who primed with abundant money concept will have a stronger self-sufficiency motivation, and believe similarity with others is a threat (Liu, Smeesters, $\&$ Vohs, 2011), so they have more unique demands in product selection (Zhao, 2014).

Therefore, it is inferred that when the concept of abundant money is primed, individuals can improve their ability to recognize and handle matters around them, even difficult tasks like nonalignable information. And they can adopt a high level of interpretation for cognition, so that they can treat problems more comprehensively and abstractly. Besides, they will also avoid being similar to the public and having more unique demands. So we propose that:

H1: When the concept of abundant (vs. lack) money is primed, consumers will rely more on nonalignable attributes than the alignable attributes.

\subsection{Cognitive Flexibility}

Cognitive flexibility is the ability of individuals to adapt tasks by adopting various strategies of cognitive processing in order to adapt to the changing new environment (Grattan \& Eslinger, 1989; Ionescu, 2012). Martin \& Rubin (1995) put forward that cognitive flexibility refers to an individual's ability to deal with conflicts by using alternative methods, which is a characteristic embodied in the individual's cognition of social situations. It contains the components of three aspects. First, individuals have a sense of being able to make multiple choices in any situation; second, individuals are willing to adapt flexibly to certain environment; third, individuals believe in their ability to cope with new situations.

Reviewing the researches on cognitive flexibility, we found that individual's cognitive flexibility is affected by many factors. For instance, when individuals adopt a more general, abstract rather than concrete perspective, their cognitive flexibility will be higher (Hossain, 2018). Duan and Huang (2013) started from the situational focus theory of power, pointing out that individuals with high power perception have more unrestricted freedom and greater personal agency, which makes them have greater selectivity in information processing, so they have higher flexibility in cognition. On the contrary, when individuals have low perception of power and weak control over resources, they will be subject to more cognitive and behavioral constraints, which will make them feel pressure and negative mood, thus undermining the cognitive flexibility. 
Previous studies have pointed out that different meanings of money priming can affect individual's cognition (Hansen, Kutzner, \& Waenke, 2013). Compared with priming the concept of lack money, when priming the concept of abundant money, individuals will have a stronger sense of control, feel less constrained and more free in the environment (Boucher \& Kofos, 2012; Zhou, Vohs, \& Baumeister, 2009). In addition, the concept of abundant money will enable individuals to use global, abstract mental construals to recognize things, so that they can handle problems more comprehensively. However, reminders of lack money should trigger more concrete mental representations, which will lead individuals to perceive things at a lower level of explanation and their attention will be excessively occupied by the specific level of content, so they aren't able to see the problem comprehensively (Hansen, Kutzner, \& Waenke, 2013; Lu, Wang, \& Fu, 2014). Therefore, we suppose that compared with reminders of lack money, when reminders of abundant money will make individuals have a sense of control to the environment, so they are more free and comprehensive in thinking, which will make them not too limited to the specific level of content, so as to be more flexible in cognition.

Researchers found that individuals with high cognitive flexibility can make use of more cognitive resources and have more ability to find other resources to solve problems. Besides, with the improvement of cognitive flexibility, individuals are more responsive, confident and insightful, so they are easier to understand and process different information, connect different fields, accept new ideas, and more inclined to view problems comprehensively from multiple perspectives (Canas et al., 2003; Herd \& Mehta, 2019; Jhang, Grant, \& Campbell, 2012). And when dealing with difficult tasks, they are easier to process relatively complex information and improve the acceptance of novel and unique information (De Dreu, Baas, \& Nijstad, 2008).

In the process of comparative decision-making, when consumers can mobilize more cognitive resources or process information on comprehensive and abstract construction (Zhang \& Fitzsimons, 1999; Sun, Keh, \& Lee, 2019), they are more inclined to use complex but unique nonalignable attributes for decision-making. Therefore, we infer that with the increase of cognitive flexibility, individuals will rely more on nonalignable attributes in the process of comparative decisionmaking. Thus, we hypothesize that:

H2: When the concept of abundant (vs. lack) money is primed, consumers' reliance on nonalignable attributes (vs. alignable attributes) is driven by cognitive flexibility.

\section{Study}

In order to eliminate the influence of brand preference and ensure that the choice of participants is caused by the different reliance on alignable attributes and nonalignable attributes rather than by the attention to individual attribute or the difference caused by the overall attributes attractiveness of the product, 
we construct virtual product $\mathrm{X}$ and product $\mathrm{Y}$ through two pre-tests in the formal experiment. We evaluate attributes' importance and attractiveness of two virtual products to ensure Product $\mathrm{X}$ has advantage in alignable attribute and Product $\mathrm{Y}$ has advantage in nonalignable attribute, but they have the same attractiveness in the whole.

\subsection{Study 1}

The purpose of Experiment 1 is to verify that different meaning of money priming will affect the consumer's reliance on alignable attribute and nonalignable attribute in comparison decision-making. Specifically, when reminder of a great deal of money, consumers will rely more on the nonalignable attributes, and when reminder of lack money, consumers will rely more on the alignable attributes.

\section{Method}

Stimuli. In Experiment 1, the stimuli selected was hotel and the researchers constructed two virtual products. The alignable attributes of $\mathrm{X}$ hotel were better than that of Y Hotel, while the nonalignable attributes of $\mathrm{Y}$ hotel were better than that of $X$ hotel. See Table 1 for the detailed product attributes.

36 participants $(18$ females, average age $=20.36)$ from Chinese university completed the first pre-test by evaluating each attribute's importance of hotel to determine three groups of attributes in Table 1 of the stimuli: alignable attributes, nonalignable attributes of Hotel $\mathrm{X}$ and nonalignable attributes of hotel $\mathrm{Y}$. The results show that there is no significant difference in the importance of attribute between hotel $\mathrm{X}$ and hotel $\mathrm{Y}$. Specifically, there was no significant difference in the importance of alignable and nonalignable attributes between hotel $\mathrm{X}\left(\mathrm{M}_{\mathrm{X}}\right.$ alignable $\left.=5.52, \mathrm{M}_{\mathrm{X} \text { nonalignable }}=5.56, p=0.834\right)$. There was no significant difference in the importance of alignable and nonalignable attributes between Hotel $\mathrm{Y}\left(\mathrm{M}_{\mathrm{Y}}\right.$ alignable $=5.52, \mathrm{M}_{\mathrm{Y} \text { nonalignable }}=5.48, p=0.832$ ). In addition, there was no significant difference in the importance of nonalignable attributes between the two hotels $\left(\mathrm{M}_{\mathrm{X} \text { nonalignable }}=5.56, \mathrm{M}_{\mathrm{Y} \text { nonalignable }}=5.48, p=0.66\right)$.

40 participants $(17$ females, average age $=20.08)$ from Chinese university

Table 1. Attributes of two virtual product.

\begin{tabular}{|c|c|c|}
\hline & Hotel X & Hotel Y \\
\hline \multirow{3}{*}{$\begin{array}{l}\text { Alignable } \\
\text { attributes }\end{array}$} & High service timeliness & Low service timeliness \\
\hline & $\begin{array}{l}\text { Room sound insulation effect is } \\
\text { wonderful }\end{array}$ & Room sound insulation effect is average level \\
\hline & Convenient booking process & Complicated booking process \\
\hline \multirow[t]{3}{*}{$\begin{array}{l}\text { Nonalignable } \\
\text { attributes }\end{array}$} & $\begin{array}{l}\text { Responsibility of security personnel } \\
\text { is average level }\end{array}$ & Comfortable environment \\
\hline & Some hotel staff are not very friendly & Convenient transportation near the hotel \\
\hline & Not always accurate billing & Perfect fire protection system \\
\hline
\end{tabular}


completed the second pre-test by evaluating each attribute's attractiveness. The results showed that there was no difference in the overall attractiveness between the two hotels $\left(\mathrm{M}_{\mathrm{Hotel}}=4.07, \mathrm{M}_{\mathrm{Hotel} \mathrm{Y}}=4.07, p>0.05\right)$. But the alignable attributes' attractiveness of Hotel $\mathrm{X}$ is significantly higher than that of Hotel $\mathrm{Y}$ $\left(\mathrm{M}_{\mathrm{Hotel} \mathrm{X}}=5.8, \mathrm{M}_{\mathrm{Hotel} \mathrm{Y}}=2.2, p<0.05\right)$ and the nonalignable attributes' attractiveness of Hotel $\mathrm{Y}$ is significantly higher than that of Hotel X $\left(\mathrm{M}_{\mathrm{Hotel}}=2.3\right.$, $\left.\mathrm{M}_{\text {Hotel Y }}=5.9, p<0.05\right)$.

Experimental Design and Procedure. The experiment used a 2 (money priming: abundant money vs. lack money) ${ }^{\star} 2$ (product: superior alignable Hotel $\mathrm{X}$ vs.superior nonalignable Hotel Y) mixed design, with product being a within-participant factor. 81 undergraduate students (49 females, 32 males, average age $=22.55)$ from Chinses university participated in the study in exchange for course credit. The dependent variable is the purchase intention of two products.

First, participants were randomly assigned to two money priming conditions. In the abundant money priming condition, participants were presented with pictures of large denomination bills, in the lack money priming condition, participants were presented with pictures of small coins (Hansen, Kutzner, \& Waenke, 2013). Then they were asked to read the information about the two products carefully and to indicate their purchase likelihood for each of the two products on a 7-point scale. Last, they were asked how attractive each attribute was $(1=$ extremely unattractive; 7 = extremely attractive).

\section{Result}

Manipulations Checks. The construction of two products based on their attribute attractiveness was found to be appropriate. Paricipants rated that there was no significant difference in the overall attractiveness between Hotel $\mathrm{X}$ and Hotel $\mathrm{Y}\left(\mathrm{M}_{\mathrm{X}}=4.27, \mathrm{M}_{\mathrm{Y}}=4.19, \mathrm{t}(80)=1.37, p=0.173\right)$; the alignable attribute of Hotel $\mathrm{X}$ was more attractive than that of Hotel $\mathrm{Y}\left(\mathrm{M}_{\mathrm{X}}=6.04, \mathrm{M}_{\mathrm{Y}}=2.32\right.$; $\mathrm{t}(80)=$ $30.776, p<0.001)$, the nonalignable attribute of Hotel $\mathrm{Y}$ was more attractive than that of Hotel $\mathrm{X}\left(\mathrm{M}_{\mathrm{X}}=2.44, \mathrm{M}_{\mathrm{Y}}=5.95 ; \mathrm{t}(80)=-28.65, p<0.001\right)$. That is to say, in line with the results of pre-test, the construction of two hotels is appropriate.

Purchase Intention. We used a 2 (money priming) * 2 (product) mixed-design ANOVA to analyze participants' purchase intention, with product as a within-participant factor. The results showed that neither the main effect of money priming $(\mathrm{F}(1,80)=0.2, p>0.05)$ nor product type $(\mathrm{F}(1,80)=0.18, p>0.05)$ was significant. Importantly, the expected money priming * product interaction effect was significant $(F(1,80)=19.15, p<0.05)$. Specifically, in the lack money priming condition, participants' purchase intention was significantly higher for the Hotel $\mathrm{X}$ than for the Hotel $\mathrm{Y}\left(\mathrm{M}_{\mathrm{X}}=4.71, \mathrm{M}_{\mathrm{Y}}=3.46, \mathrm{t}(40)=3.477, p<0.05\right)$; in the abundant money priming condition, participants' purchase intention was significantly higher for the Hotel $\mathrm{Y}$ than for the Hotel $\mathrm{X}\left(\mathrm{M}_{\mathrm{X}}=3.62, \mathrm{M}_{\mathrm{Y}}=4.65, \mathrm{t}\right.$ $(40)=-2.731, p<0.05)($ See Figure 1$)$.

\section{Discussion}

Studyl showed that different meanings of money priming do affect consum- 
ers' reliance on different attributes in comparative decision-making. Specifically, when the concept of abundant money is primed, consumers are more likely to rely on nonalignable attribute and when the concept of lack money is primed, consumers are more likely to rely on alignable attributes to make decisions in comparative decisions making process.

\subsection{Study 2}

The purpose of study 2 is to verify again that reminder of abundant money, consumers will rely more on the nonalignable attributes, and when reminder of lack money, consumers will rely more on the alignable attributes. And further prove this difference is driven by individuals' cognitive flexibility.

\section{Method}

Stimuli. In study 2, the stimuli selected was restaurant and the researchers constructed two virtual products. The alignable attributes of Restaurant $\mathrm{X}$ were better than that of Restaurant $\mathrm{Y}$ while the nonalignable attributes of Restaurant $\mathrm{Y}$ were better than that of Restaurant X. See Table 2 for the detailed product attributes.

36 participants $(18$ females, average age $=20.36)$ from Chinese university completed the first pre-test by evaluating each attribute's importance of restaurant to determine three groups of attributes in Table 2 of the stimuli: alignable attributes, nonalignable attributes of Restaurant $\mathrm{X}$ and nonalignable attributes of

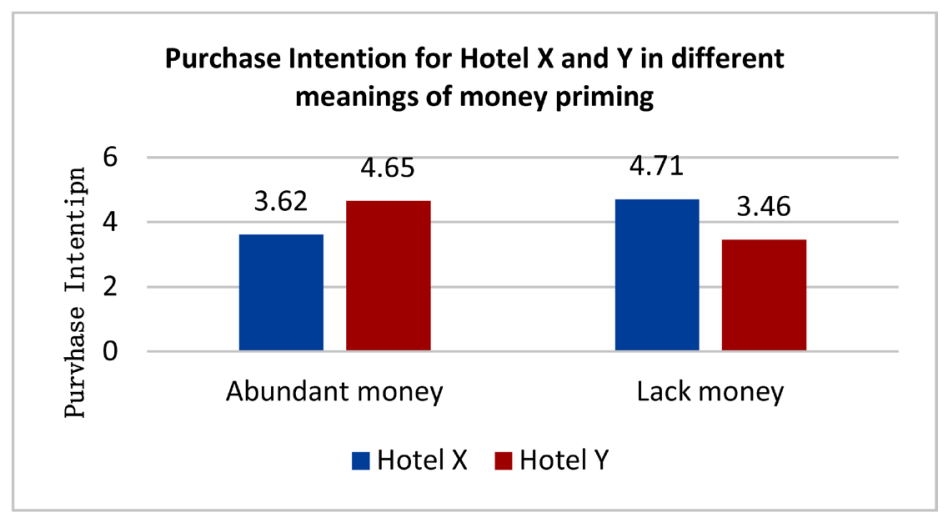

Figure 1. Purchase Intention for Hotel $\mathrm{X}$ and $\mathrm{Y}$ in different meanings of money priming.

Table 2. Attributes of two virtual product.

\begin{tabular}{|c|c|c|}
\hline & Restaurant X & Restaurant Y \\
\hline \multirow{3}{*}{$\begin{array}{l}\text { Alignable } \\
\text { attributes }\end{array}$} & Food with high quality & Food with moderate quality \\
\hline & Rich kinds of dishes & Limited kinds of dishes \\
\hline & Convenient booking process & Complicated booking process \\
\hline \multirow{2}{*}{$\begin{array}{l}\text { Nonalignable } \\
\text { attributes }\end{array}$} & Long waiting time for dishes & Service staff have good manner \\
\hline & $\begin{array}{l}\text { The service provided by the restaurant is not } \\
\text { timely }\end{array}$ & Fresh ingredients \\
\hline
\end{tabular}


Restaurant Y. The results show that there is no significant difference in the importance of attribute between Restaurant $\mathrm{X}$ and Restaurant $\mathrm{Y}$. Specifically, there was no significant difference in the importance of alignable and nonalignable attributes between Restaurant $\mathrm{X}\left(\mathrm{M}_{\mathrm{X} \text { alignable }}=5.47, \mathrm{M}_{\mathrm{X} \text { nonalignable }}=5.41, p=0.934\right)$. There was no significant difference in the importance of alignable and nonalignable attributes between Restaurant $\mathrm{Y}\left(\mathrm{M}_{\mathrm{Y} \text { alignable }}=5.47, \mathrm{M}_{\mathrm{Y} \text { nonalignable }}=\right.$ $5.45, p=0.834)$. In addition, there was no significant difference in the importance of nonalignable attributes between the two hotels $\left(\mathrm{M}_{\mathrm{X} \text { nonalignable }}=5.41, \mathrm{M}_{\mathrm{Y}}\right.$ nonalignable $=5.45, p=0.764)$.

40 participants $(17$ females, average age $=20.08)$ from Chinese university completed the second pre-test by evaluating each attribute's attractiveness. The results showed that there was no difference in the overall attractiveness between the two hotels $\left(\mathrm{M}_{\text {Restaurant } \mathrm{X}}=4.0, \mathrm{M}_{\text {Restaurant } \mathrm{Y}}=3.88, p>0.05\right)$. But the alignable attributes' attractiveness of Hotel $\mathrm{X}$ is significantly higher than that of Hotel $\mathrm{Y}$ $\left(\mathrm{M}_{\text {Restaurant X }}=5.79, \mathrm{M}_{\text {Restaurant } \mathrm{Y}}=2.17, p<0.05\right)$ and the nonalignable attributes' attractiveness of Hotel $\mathrm{Y}$ is significantly higher than that of Hotel $\mathrm{X}\left(\mathrm{M}_{\mathrm{Hotel} X}=\right.$ 2.22, $\left.\mathrm{M}_{\text {Hotel Y }}=5.59, p<0.05\right)$.

Experimental Design and Procedure. The experiment used a 2 (money priming: abundant money vs. lack money) ${ }^{\star} 2$ (product: superior alignable Restaurant $\mathrm{X}$ vs. superior nonalignable Restaurant $\mathrm{Y}$ ) mixed design, with product being a within-participant factor. 71 undergraduate students ( 43 females, average age = 23.62) from Chinese university participated in the study in exchange for course credit. The dependent variable is the purchase intention of two products.

First, participants were randomly assigned to two money priming conditions and read the information about the two products carefully and to indicate their purchase intention for each of the two products on a 7-point scale as Study 1. Then cognitive flexibility was measured by categorical inclusion task (Chen, Zheng, \& Fan, 2013). Last, they were asked how attractive each attribute was ( $1=$ extremely unattractive; 7 = extremely attractive).

\section{Result}

Manipulations Checks. The construction of two products based on their attribute attractiveness was found to be appropriate. Participants rated that there was no significant difference in the overall attractiveness between Restaurant $\mathrm{X}$ and Restaurant $\mathrm{Y}\left(\mathrm{M}_{\mathrm{X}}=4.05, \mathrm{M}_{\mathrm{Y}}=4.15, \mathrm{t}(71)=-1.562, p=0.123\right)$; the alignable attribute of Restaurant $\mathrm{X}$ was more attractive than that of Restaurant $\mathrm{Y}\left(\mathrm{M}_{\mathrm{X}}\right.$ $\left.=5.69, \mathrm{M}_{\mathrm{Y}}=2.7 ; \mathrm{t}(71)=18.103, p<0.001\right)$, the nonalignable attribute of Restaurant $\mathrm{Y}$ was more attractive than that of Restaurant $\mathrm{X}\left(\mathrm{M}_{\mathrm{X}}=2.41, \mathrm{M}_{\mathrm{Y}}=5.61 ; \mathrm{t}\right.$ $(71)=-20.889, p<0.001)$. That is to say, in line with the results of pre-test, the construction of two restaurants is appropriate.

Purchase Intention. We used a 2 (money priming) * 2 (product) mixed-design ANOVA to analyze participants' purchase intention, with product as a within-participant factor. The results showed that neither the main effect of money priming $(\mathrm{F}(1,68)=1.328, p>0.05)$ nor product type $(\mathrm{F}(1,68)=0.079, p>$ 
$0.05)$ was significant. Importantly, the expected money priming*product interaction effect was significant $(F(1,68)=62.937, p<0.05)$. Specifically, in the lack money priming condition, participants' purchase intention was significantly higher for the Restaurant $\mathrm{X}$ than for the Restaurant $\mathrm{Y}\left(\mathrm{M}_{\mathrm{X}}=5.02, \mathrm{M}_{\mathrm{Y}}=3.6, \mathrm{t}\right.$ $(35)=5.9, p<0.05)$; in the abundant money priming condition, participants' purchase intention was significantly higher for the Restaurant $\mathrm{Y}$ than for the Restaurant $\mathrm{X}\left(\mathrm{M}_{\mathrm{X}}=3.5, \mathrm{M}_{\mathrm{Y}}=4.82, \mathrm{t}(34)=-5.52, p<0.05\right)$ in Figure 2.

Mediation. We supposed that when the concept of abundant (vs. lack) money is primed, consumers' reliance on nonalignable attributes (vs. alignable attributes) is driven by individuals' cognitive flexibility. So we created a relative purchase intention index by dividing participants' purchase intention rating of the superior-alignable product by their rating of the superior-nonalignable product (Johnson \& Krueger, 2006). Then we use Bootstrap analyses with 5000 sample size and the $95 \%$ confidence interval to test the mediation effect. The results showed that the indirect effect of cognitive flexibility on purchase intention index was significant at $95 \%$ confidence interval (LLCI $=-0.2812$, ULCI $=-0.0186$ ). However, the direct effect of money priming was still significant after adding cognitive flexibility (LLCI $=-0.8143$, ULCI $=-0.4093, p<0.05$ ). It proved that the effect of money priming on purchase intention was partially mediated by cognitive flexibility.

\section{Discussion}

Study 2 provided additional support for the hypothesis 1 by using another stimuli, which verifies the robustness of money priming's effect on consumers' reliance in the comparative decision-making process. Besides, when the concept of abundant (vs. lack) money is primed, consumers' cognitive flexibility will be higher, which leads consumers' preference to use nonalignable (vs. alignable) attribute, that is, cognitive flexibility plays a mediating role in this effect.

\section{General Discussion}

With the development of the structure alignment model, more scholars are exploring the influence factors in the process of information processing of comparative

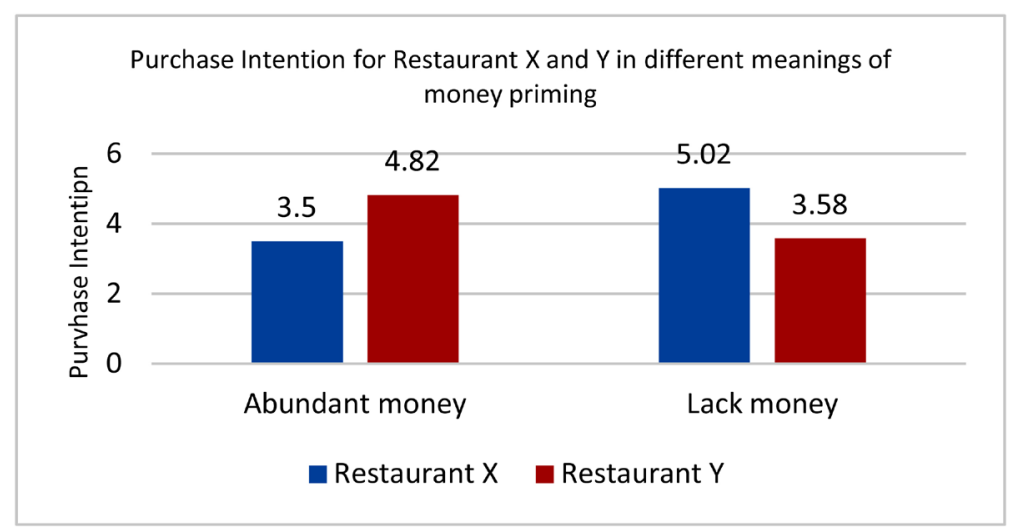

Figure 2. Purchase Intention for Restaurant $\mathrm{X}$ and $\mathrm{Y}$ in different meanings of money priming. 
decision-making. Such as cognitive ability or resources (Zhang \& Markman, 2001), information processing mode (Sun \& Wang, 2016), need for cognitive closure (Zhang, Karde, \& Cronley, 2002), or consumption goals (Murshed, Nagpa, \& Moosa, 2018), information's presentation format (Sun, 2011) etc. Based on the theory of money priming, this paper proved money as a situational factor that affects individuals' cognition and behavior, and further verifies the influence of different meanings of money priming on consumers' alignable and nonalignable attributes reliance tendency in the process of comparative decision-making. Specifically, when the concept of abundant (vs. lack) money is primed, consumers will rely more on nonalignable attributes than the alignable attributes, and this effect is mediated by cognitive flexibility.

In terms of marketing implications, as consumers have access to compare enough information between alternative products, which requires enterprises to cater for the tastes and needs of customers. In the fierce market competition, enterprises will gain competitive advantage by continuously optimizing the value of a certain attribute, or providing differentiated value which is lacking in the current market. According to the previous research findings, products that often gain advantages in alignable attributes will be more competitive. However, not all enterprises can get comparative advantage in alignable attributes, so many enterprises often choose to give products some unique nonalignable attributes to get advantage of differentiation. According to the conclusion of this study, when enterprises want to highlight the advantage of nonalignable attributes in competition, they can add some clues (such as gold decoration in shopping malls, luxury words in advertising language, etc.) in the environment to stimulate consumers' sense of wealth, so as to improve their attention and reliance to nonalignable attributes. Similarly, when enterprises want to highlight the advantages of alignable attributes in the competition, they can increase consumers' attention by adding some clues that can stimulate consumers' sense of lack or deprivation of money. That is to say, in the design or presentation of product information, enterprises can cater to consumers' psychological preferences by adding some money clues with different meanings and emphasizing different attributes.

In terms of theoretical contribution, this study enriches the research of money priming in the field of marketing. Previous research on money priming has been applied to impulse purchase (Zhang, Karde, \& Cronley, 2002; Zhao, Jing, \& Tao, 2016), need for uniqueness (Zhou et al., 2009), brand evaluation (Hansen, Kutzner, \& Waenke, 2013) etc. This paper puts forward the influence of different meanings of money priming on consumers' comparative decision-making. Furthermore, previous studies based on structural alignment model have pointed out that consumers tend to rely on the alignable attribute which is simple and easy to process in the process of comparative decision-making (Grattan \& Eslinger, 1989; Markman \& Medin, 1995; Nam, Wang, \& Lee, 2012). We propose that consumers' reliance on different attributes can be moderated by money 
priming. That is, compared with the concept of lack money priming, the concept of abundant money priming can improve consumers' reliance on the nonalignable attribute which is unique but more difficult to process.

In future research, researchers can further explore whether the same effect can be brought when the concept of money expenditure is primed. In this article, we only manipulated the money deficiency. But based on the theory of social resources and self-sufficiency, the effect of money deficiency is the same as that of money deprivation (Zhou, Vohs, \& Baumeister, 2009; Hansen, Kutzner, \& Waenke, 2013). In addition, the cognitive flexibility proposed in this paper has been proved to only play a partially mediating role in consumer's comparative decision-making. It is urgent to further explore the other psychological or cognitive mechanisms that affect consumers' reliance on different types of attributes.

\section{Conflicts of Interest}

The authors declare no conflicts of interest regarding the publication of this paper.

\section{References}

Boucher, H. C., \& Kofos, M. N. (2012). The Idea of Money Counteracts Ego Depletion Effects. Journal of Experimental Social Psychology, 48, 804-810. https://doi.org/10.1016/j.jesp.2012.02.003

Canas, J., Quesada, J., Antolí, A., \& Fajardo, I. (2003). Cognitive Flexibility and Adaptability to Environmental Changes in Dynamic Complex Problem-Solving Tasks. Ergonomics, 46, 482-501. https://doi.org/10.1080/0014013031000061640

Chen, H. H., Zheng, Y. H., \& Fan, X. M. (2013). The Effects of Chaotic Physical Environments on Creativity. Journal of Marketing Science, No. 4, 90-100. (In Chinese)

De Dreu, C. K. W., Baas, M., \& Nijstad, B. A. (2008). Hedonic Tone and Activation Level in the Mood-Creativity Link: Toward a Dual Pathway to Creativity Model. Journal of Personality and Social Psychology, 94, 739-756.

Duan, J. Y., \& Huang, C. Y. (2013). The Mechanism of Employee's Sense of Power on Speaking-Up: A Power Cognition Perspective. Acta Psychologica Sinica, 45, 217-230.(In Chinese) https://doi.org/10.3724/SP.J.1041.2013.00217

Gentner, D., \& Markman, A. B. (1994). Structural Alignment in Comparison: No Difference without Similarity. Psychological Science, 5, 152-158. https://doi.org/10.1111/j.1467-9280.1994.tb00652.x

Gentner, D., \& Markman, A. B. (1997). Structural Alignment in Analogy and Similarity. American Psychologist, 52, 45-56. https://doi.org/10.1037/0003-066X.52.1.45

Goldberg, H., \& Lewis, R. T. (2000). Money Madness: The Psychology of Saving, Spending, Loving, and Hating Money. New York: William Morrow.

Grattan, L. M., \& Eslinger, P. J. (1989). Higher Cognition and Social Behavior: Changes in Cognitive Flexibility and Empathy after Cerebral Lesions. Neuropsychology, 3, 175-185.

Hansen, J., Kutzner, F., \& Waenke, M. (2013). Money and Thinking: Reminders of Money Trigger Abstract Construal and Shape Consumer Judgments. Journal of Consumer Research, 39, 1154-1166. https://doi.org/10.1086/667691

Herd, K. B., \& Mehta, R. (2019). Head versus Heart: The Effect of Objective versus Feelings-Based Mental Imagery on New Product Creativity. Journal of Consumer Research, 
46, 36-52. https://doi.org/10.1093/jcr/ucy058

Hossain, M. T. (2018). How Cognitive Style Influences the Mental Accounting System: Role of Analytic versus Holistic Thinking. Journal of Consumer Research, 45, 615-632. https://doi.org/10.1093/jcr/ucy020

Ionescu, T. (2012). Exploring the Nature of Cognitive Flexibility. New Ideas in Psychology, 30, 190-200. https://doi.org/10.1016/j.newideapsych.2011.11.001

Jhang, J. H., Grant, J. S., \& Campbell, M. C. (2012). Get It? Got It. Good! Enhancing new Product Acceptance by Facilitating Resolution of Extreme Incongruity. Journal of Marketing Research, 49, 247-259. https://doi.org/10.1509/jmr.10.0428

Johnson, W., \& Krueger, R. F. (2006). How Money Buys Happiness: Genetic and Environmental Processes. Journal of Personality and Social Psychology, 90, 680-691. https://doi.org/10.1037/0022-3514.90.4.680

Kivetz, R., \& Simonson, I. (2000). The Effects of Incomplete Information on Consumer Choice. Journal of Marketing Research, 37, 427-448.

https://doi.org/10.1509/jmkr.37.4.427.18796

Kotler, P., Keller, K., Brady, M., Goodman, M., \& Hansen, T. (2009). Marketing Management: First European Edition. London: Pearson.

Liu, J., Smeesters, D., \& Vohs, K. D. (2011). Retracted: Reminders of Money Elicit Feelings of Threat and Reactance in Response to Social Influence. Journal of Consumer Research, 38, 1030-1046. https://doi.org/10.1086/661553

Lu, X. K., Wang, X. J., \& Fu, X. Y. (2014). Why Poverty Weakens Decision-Making Ability? Three Psychological Explanations. Advances in Psychological Science, 22, 1823-1828. (In Chinese) https://doi.org/10.3724/SP.J.1042.2014.01823

Malkoc, S. A., Zauberman, G., \& Ulu, C. (2005). Consuming Now or Later? The Interactive Effect of Timing and Attribute Alignability. Psychological Science, 16, 411-417. https://doi.org/10.1111/j.0956-7976.2005.01549.x

Markman, A. B., \& Medin, D. L. (1995). Similarity and Alignment in Choice. Organizational Behavior and Human Decision Processes, 63, 117-130. https://doi.org/10.1006/obhd.1995.1067

Martin, M. M., \& Rubin, R. B. (1995). A New Measure of Cognitive Flexibility. Psychological Reports, 76, 623-626. https://doi.org/10.2466/pr0.1995.76.2.623

Matthews, A. M. (1991). If I Think about Money So Much, Why Can't I Figure It out?: Understanding and Overcoming Your Money Complex. Pocket.

Mogilner, C. (2010). The Pursuit of Happiness: Time, Money, and Social Connection. Psychological Science, 21, 1348-1354. https://doi.org/10.1177/0956797610380696

Murshed, F., Nagpal, A., \& Moosa, A. (2018). Self-Customisation and Attribute Alignability: Role of Utilitarian versus Hedonic Consumption. Journal of Research for Consumers, No. 33, 83-115.

Nam, M., Wang, J., \& Lee, A. Y. (2012). The Difference between Differences: How Expertise Affects Diagnosticity of Attribute Alignability. Journal of Consumer Research, 39, 736-750. https://doi.org/10.1086/664987

Sun, J. (2010). Review and Prospect of Structural Alignment Model Research: A New Trend of Consumer Behavior Development. East China Economic Management, No. 4, 154-158. (In Chinese)

Sun, J. (2011). The Influence of Attribute Comparability on Consumer Brand Evaluation: The Moderating Effect of Evaluation Model. Management Review, 23, 103-111. (In Chinese)

Sun, J. (2014). A Study on the Comparative Decision-Making Process of Consumers: The 
Moderating Effect of Specialization Level and Purchase Situation. Management Review, No. 9, 191-198. (In Chinese)

Sun, J., \& Wang, Y. G. (2016). "Only the Trees” or "The Whole Forest”-The Moderating Effect of Gender on the Process of Consumer Comparative Information Processing. Nankai Management Review, No. 19, 97. (In Chinese)

Sun, J., Keh, H. T., \& Lee, A. Y. (2019). Shaping Consumer Preference Using Alignable Attributes: The Roles of Regulatory Orientation and Construal Level. International Journal of Research in Marketing, 36, 151-168. https://doi.org/10.1016/j.ijresmar.2018.12.001

Vohs, K. D., Mead, N. L., \& Goode, M. R. (2006). The Psychological Consequences of Money. Science, 314, 1154-1156. https://doi.org/10.1126/science.1132491

Zhang, S., \& Fitzsimons, G. J. (1999). Choice-Process Satisfaction: The Influence of Attribute Alignability and Option Limitation. Organizational Behavior and Human Decision Processes, 77, 192-214. https://doi.org/10.1006/obhd.1999.2821

Zhang, S., \& Markman, A. B. (1998). Overcoming the Early Entrant Advantage via Differentiation: The Role of Alignable and Nonalignable Differences. Journal of Marketing Research, 35, 413-426. https://doi.org/10.1177/002224379803500401

Zhang, S., \& Markman, A. B. (2001). Processing Product Unique Features: Alignability and Involvement in Preference Construction. Journal of Consumer Psychology, 11, 13-27. https://doi.org/10.1207/S15327663JCP1101_2

Zhang, S., Kardes, F. R., \& Cronley, M. L. (2002). Comparative Advertising: Effects of Structural Alignability on Target Brand Evaluations. Journal of Consumer Psychology, 12, 303-311.

Zhao, J. B. (2014). Research on the Influence of Money Concept on Consumers' Unique Needs. Psychological Science, No. 6, 183-188. (In Chinese)

Zhao, J. B., Jing, F. J., \& Tao, J. R. (2016). Research on the Influence Mechanism of Money Concept on Impulse Purchase Intention. Journal of Donghua University of Technology: Social Science Edition, No. 35, 43. (In Chinese)

Zhou, X., Vohs, K. D., \& Baumeister, R. F. (2009). The Symbolic Power of Money: Reminders of Money Alter Social Distress and Physical Pain. Psychological Science, 20, 700-706. https://doi.org/10.1111/j.1467-9280.2009.02353.x 